\title{
Expression of Ki67 in Precancerous Squamous Cell Skin Lesion of Mice Induced by DMBA
}

\author{
Siti Nurkasanah ${ }^{1}$, Aida S D Hoemardani ${ }^{2}$, Evlina Suzanna Sinuraya ${ }^{3}$ \\ ${ }^{1}$ Department of Oncology, Magister Program in Biomedical Science, Faculty of Medicine, Universitas Indonesia, Jakarta, \\ Indonesia \\ ${ }^{2}$ Department of Dermatology, National Cancer Center-Dharmais Cancer Hospital, Jakarta, Indonesia \\ ${ }^{3}$ Department of Anatomical Pathology, National Cancer Center-Dharmais Cancer Hospital, Jakarta, Indonesia
}

\section{ARTICLE INFO}

Received : 18 April 2019

Reviewed: 14 May 2019

Accepted : 01 June 2019

\section{Keywords:}

fluorouracil, Ki67, precancerous squamous cell, skin, topical treatment
*Corresponding author:

Aida S D Hoemardani

Department of Dermatology,

National Cancer Center-Dharmais

Cancer Hospital, Jakarta, Indonesia.

Email: aida.hoemardani@gmail.com

\begin{abstract}
A BSTRACT
Background: Squamous cell carcinoma (SCC) is an invasive skin cancer that is found in the human skin. SCC growth from the precancerous lesion is known as a wart or papilloma. Ki67 is a protein expressed by cells during proliferation. Cells with higher Ki67 expression showed abnormal regulation of apoptosis. 5-FU is an antimetabolite compound that works as a DNA/RNA pyrimidine antagonist molecule that can induce cell apoptosis. The main objective of this research is to evaluate the inhibition proliferation of precancerous squamous cell in skin lesion induced by DMBA/croton oil treated by using 5 -FU cream topically compared to $5 \%$ imiquimod cream.
\end{abstract}

\begin{abstract}
Methods: This research assesses three different concentrations of 5-FU cream namely $1 \%, 2 \%$, and $5 \%$ topically on 24 wild type mice divided into 6 groups of 4 each including positive control (with carcinogenesis but without treatment), negative control (without treatment ; normal), carcinogenesis with treatment 5 -FU cream (1\%, $2 \%$, and $5 \%$ ) or $5 \%$ imiquimod cream. The expression of Ki67 was analyzed using immunohistochemistry. Statistical analysis was performed by one-way ANOVA using SPSS version 23.
\end{abstract}

Results: Based on this research, 5-FU cream treatment during 4 weeks (week 10-week 14) showed the decrease of cumulative number of papilloma $(p<0.05)$ and immunohistochemistry analysis resulted in the lowest Ki67 expression in 5-FU 2\% and $5 \%$ groups compared to $5 \%$ imiquimod cream $(p<0.05)$.

Conclusions: 5-FU cream treatment during 4 weeks showed a decrease of papilloma and Ki67 expression in 5-FU cream 2\% and 5\%.

\section{INTRODUCTION}

Proliferation is an important characteristic of invasive cancer, including skin cancer. Skin cancer is a multifactorial disease caused by heredity and several environmental factors [1]. This disease develops in the epidermis and mainly distinguished into three types including basal cell carcinoma, squamous cell carcinoma, and melanoma. Squamous cell carcinoma (SCC) is the second most common type of skin cancer and it can be invasive if not treated in the early stage (precancerous lesion). In the precancerous lesions, the skin cells lead to DNA damage and make them uncontrollably proliferate to be invasive cancer [2].

Marker for proliferation that has been widely used is Ki67. Ki67 is a non-histone protein expressed by the nucleus during cell cycle phases (G1-M) [3]. The protein increases during the $M$ phase and decreases during $\mathrm{G} 1$ and $\mathrm{S}$ phases [4]. The expression of Ki67 is related to the growth fraction and absent during DNA repair process. This protein regulates the proteolytic pathway and is controlled by cyclin B/cyclin-dependent kinase 2 [3].

One of the most developed treatments for precancerous squamous cell skin lesion in National Cancer Center-Dharmais Cancer Hospital is topical 5Fluorouracil (5-FU; concentration 1\%, 2\%, and 5\%). 5Fluorouracil is an antimetabolite compound that works as a pyrimidine antagonist in DNA and RNA synthesis [5]. This compound enters the cell in a similar way as uracil. 5-FU changes into active metabolite such as fluorodeoxyuridine monophosphate (FdUMP), fluorodeoxyuridine triphosphate (FdUTP) and fluorouridine triphosphate (FUTP) [6]. Furthermore, it causes activation of p53 and dysfunction of mitochondria in releasing cytochrome $\mathrm{c}$ and then 
induces the apoptosis pathway [7]. However, this research was designed to evaluate the effectivity of 5FU cream from National Cancer Center-Dharmais Cancer Hospital product for squamous cell precancerous lesion through Ki67 expression compared with 5\% imiquimod cream commercial product.

\section{METHODS}

\section{Animals}

Twenty four female Swiss Webster mice 6 weeks of age divided into 6 groups of 4 each including positive control (with carcinogenesis but without treatment), negative control (without treatment; normal), carcinogenesis with treatment (5-FU $1 \%, 2 \%$, and $5 \%$ ) or imiquimod cream $5 \%$. Those mice were obtained from the animal facility of the Animal Laboratory, Agency of Health Research \& Development, Ministry of Health, Republic of Indonesia. The animals weigh between 2030 gram and free of pathogen. The mice were kept in a room with ventilation (12/12; light/dark cycle), controlled temperature $\left(19.3-23^{\circ} \mathrm{C}\right)$, relative humidity (44-74\%), given water and balanced diet ad libitum. The study has been approved by the Ethical Committee of FKUI-RSCMNo:1159/UN2.F1/ETIK/2017.

\section{Carcinogenesis model}

The carcinogen 7.12-dimethylbenzen[a]-anthracene (DMBA) (Sigma-Aldrich, USA) was used with concentration of $500 \mathrm{nmol} / 100 \mu \mathrm{l}$ acetone. Each animal was topically treated with DMBA twice a week [8]. Then after two weeks, mice were topically treated with croton oil (CO) (Sigma-Aldrich, USA) with concentration of $1 \%$ in $100 \mu$ l acetone, three times a week for up to 10 weeks then a biopsy was taken [9]. The lesions were topically treated using 5-FU cream (1\%, 2\%, and 5\%) once daily compared with $5 \%$ imiquimod cream 3 times/week for 4 weeks, and then the mice were sacrificed by performing cervical dislocation. The schematic process can be seen in Figure 1.

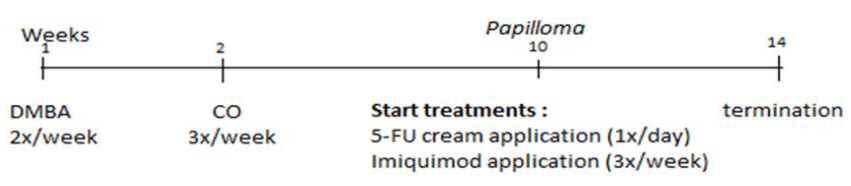

Figure 1. Process and timeline of research

\section{Histopathological study}

All mice tumor tissues and normal skin tissues were fixed in formalin (10\%), embedded in paraffin, of sections $(5 \mu \mathrm{m})$ were cut using a rotary microtome and stained with hematoxylin and eosin [10]. All histopathological result was determined by pathologist
ESS and after being fixed it proceeded to immunohistochemistry staining.

\section{Immunohistochemistry staining}

Paraffin blocks were sliced into $4 \mu \mathrm{m}$ sections using microtome and the tissue slices were placed on positive charge glass overnight. Then the slides were heated at $60^{\circ} \mathrm{C}$ for 1 hour and continued to deparaffinization in xylene (5 minutes, 3 times) and serial alcohol (5 minutes, 3 times). Antigen retrieving process was performed in Tris-EDTA pH 9.0 by incubation at $80^{\circ} \mathrm{C}$ for 12 hours in a water bath.

Afterward, slides were washed with Phosphate Buffer Saline twice for 5 minutes each. Endogenous peroxidase blocking was done with Peroxide Block (UltraTek Complete HRP Anti-Polyvalent (DAB) staining system) (Scytex LaboratoriesInc., TES-IFU Revision1) for 10 minutes at room temperature (RT), then at Super Block for 20 minutes at RT. Then, slides were treated with rabbit anti-human Ki67 antibody ready to use (Scytex Laboratories Inc. RTU, A00095-IFU-IVD) incubated at $4^{\circ} \mathrm{C}$ for 12 hours. After that, incubation was continued on UltraTek Complete HRP AntiPolyvalent for 10 minutes at RT and UltraTek HRP for 10 minutes at RT. Finally, DAB chromogen/substrate was applied for 3 minutes at RT and continued with counterstain. Slides were evaluated under a light microscope and captured using Aperio AT Turbo Slide scanner. The positive calculation was calculated using the formula: *Labeling index $=\left(\sum\right.$ positive cells $) /\left(\sum\right.$ total cells) $\times 100 \%$

\section{RESULTS}

In this research, the body weight of the mice was calculated along the research process. ANOVA analysis showed no significant difference between groups $(p>0.05)$ (Figure 2 ) while the cumulative number of papilloma showed a significant difference among the groups ( $p=0.001$ ) (Table 1 ).

Bonferroni analysis showed carcinogen control group (DMBA/CO) was significantly different compared to 5 -FU $5 \%$ group and imiquimod $5 \%(p=0.003)$ while for group therapy was significantly difference on 5 -FU $1 \%$ compared with imiquimod $5 \%(p=0.000)$ (Table 1).

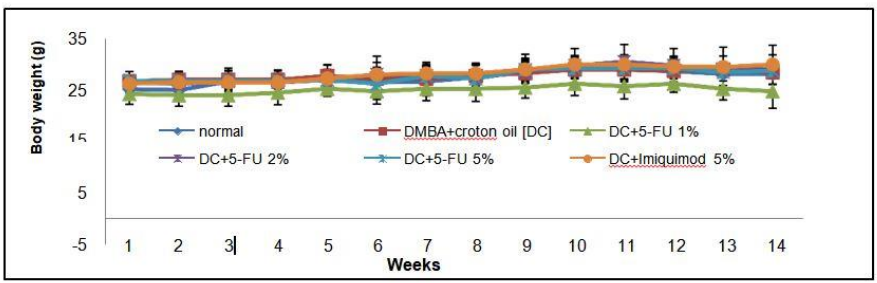

Figure 2. Body weight of mice along the research process 
Table 1. Cumulative number of papilloma in mice before and after treatment

\begin{tabular}{|c|c|c|c|c|}
\hline \multirow[b]{2}{*}{ Groups } & \multicolumn{2}{|c|}{ Before therapy } & \multicolumn{2}{|c|}{ After therapy } \\
\hline & $\underset{\text { papil }}{\Sigma}$ & $\begin{array}{c}\bar{x} \\
\text { Volume } \\
\text { of papil } \\
\left(\mathrm{mm}^{3}\right)\end{array}$ & $\underset{\text { papil }}{\Sigma}$ & $\begin{array}{c}\bar{x} \\
\text { Volume } \\
\text { of papil } \\
\left(\mathrm{mm}^{3}\right)\end{array}$ \\
\hline Normal (negative control) & 0 & 0.00 & 0 & 0.00 \\
\hline $\begin{array}{l}\text { DMBA+croton oil (positive } \\
\text { control) }\end{array}$ & 6 & 8.66 & 6 & 22.97 \\
\hline 5-FU $1 \%$ therapy & 16 & 222.70 & 16 & 138.63 \\
\hline 5-FU 2\% therapy & 12 & 45.84 & 12 & 19.74 \\
\hline 5-FU 5\% therapy & 8 & 29.59 & 8 & 14.76 \\
\hline Imiquimod 5\% therapy & 8 & 57.22 & 8 & 22.14 \\
\hline
\end{tabular}

HE staining showed that the skin structure changed after being treated topically with DMBA/CO. Figure 3a is showing normal skin structure containing clear epidermis layer, dermis, and subcutis, while in papilloma or precancerous squamous cell skin lesion the layers cannot be clearly distinguished as dysplasia, stromal damage, hyperkeratosis, acanthosis, or keratinous pearl (Figure $3 \mathbf{b}$ ).

Ki67 expression in the cells that showed brown color in the nucleus was considered to be positive. In this research, breast carcinoma was used for control positive (Figure 4a), control negative without antibody treatment (Figure $\mathbf{4 b}$ ), and precancerous squamous cell without treatment (Figure 4c), after treatment 5-FU 1$5 \%$ (Figure $4 \mathbf{d}-\mathrm{e}$ ) and after treatment of imiquimod cream (Figure 4g).

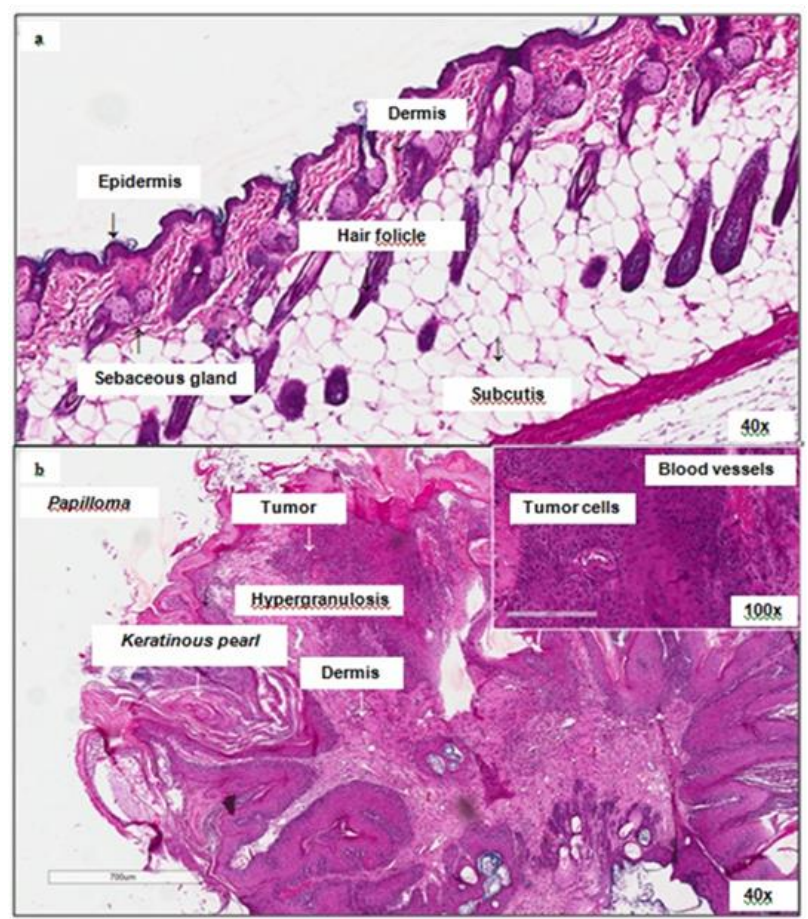

Figure 3. Normal skin structure (a) and papilloma skin structure (b) in HE staining

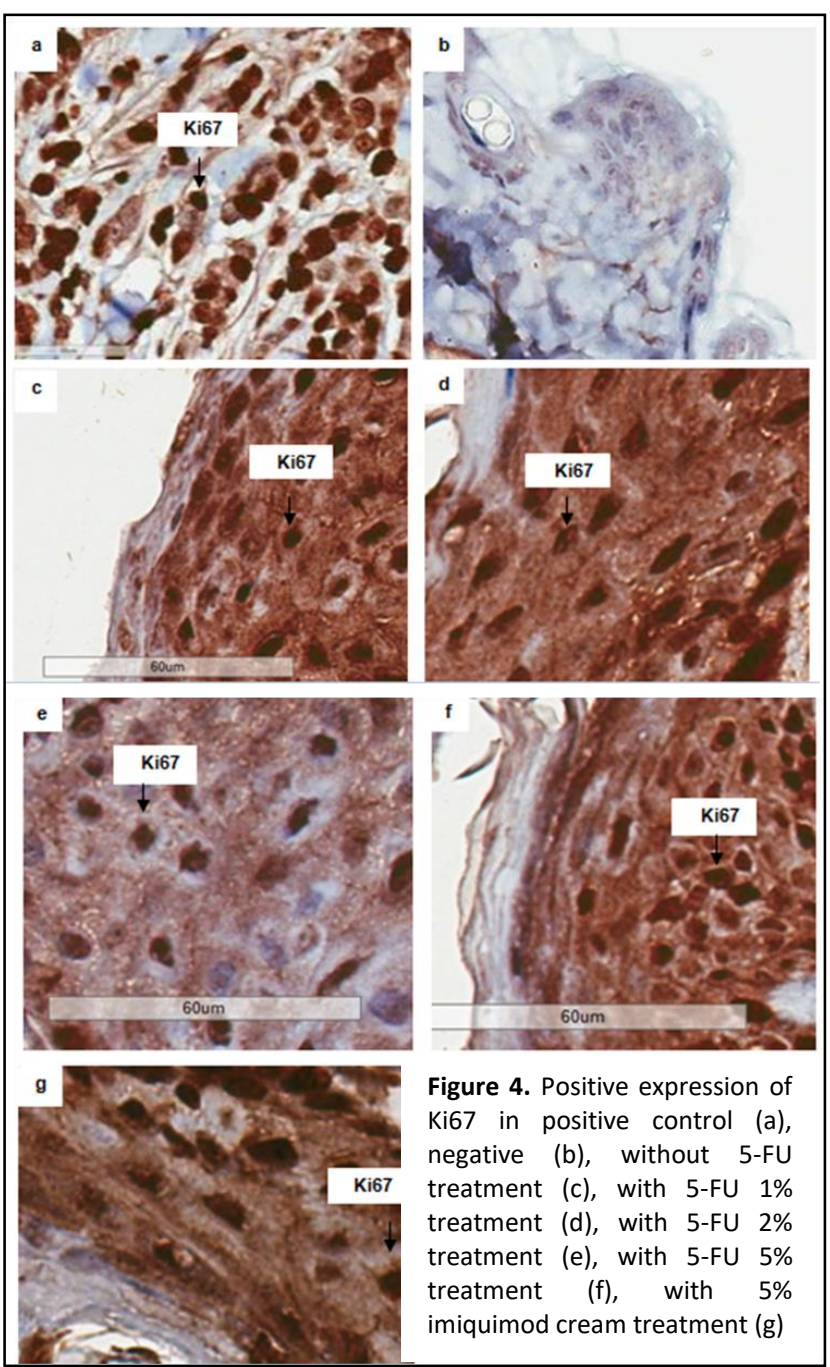

Table 2. Labeling index (LI) of Ki67 expression for all groups

\begin{tabular}{lc}
\hline \multicolumn{1}{c}{ Groups } & $\begin{array}{c}\text { Mean } \\
\text { *labeling index (\%) }\end{array}$ \\
\hline Normal (negative control) & 46.79 \\
DMBA+croton oil (positive control) & 64.20 \\
5-FU 1\% therapy & 49.65 \\
5-FU 2\% therapy & 42.63 \\
5-FU 5\% therapy & 36.23 \\
Imiquimod 5\% therapy & 67.34 \\
\hline
\end{tabular}

Table 2 showed that the labeling index (LI) Ki67 expression in the normal group $(46.79 \pm 2.47)$ was lower than the precancerous squamous cell without treatment (DMBA+croton oil). For therapy groups, the lowest Ki67 expression was found in 5-FU 5\% group $(p=0.001)$ and $5-$ FU $2 \%$ group $(p=0.006)$, while the highest Ki67 expression was in $5 \%$ imiquimod cream. The cut-off value was $30 \%$ similar to the SCC cases. This research resulted in 2 cases (8.3\%) of Ki67 which were classified as low proliferation, while 22 cases $(91.67 \%)$ were classified as high proliferation, as shown in Table 3. 
Table 3. Ki67 expression based on cut-off value of $30 \%$

\begin{tabular}{ccc}
\hline $\begin{array}{c}\text { Ki67 expression } \\
\text { (\%) }\end{array}$ & Case & Percentage \\
\hline$<30 \%$ & $2 / 24$ & $8,3 \%$ \\
$\geq 30 \%$ & $22 / 24$ & $91,67 \%$ \\
\hline
\end{tabular}

\section{DISCUSSION}

The main objective of this research was to evaluate the effectivity of 5-FU cream as a product of National Cancer Center-Dharmais Cancer Hospital for precancerous squamous cell skin lesion through Ki67 expression compared with $5 \%$ imiquimod cream, a commercial product. Swiss Webster mice were used as an animal model induced with DMBA/Croton oil to make two-stage skin carcinogenesis; DMBA as the first stage, CO as the second. DMBA has been chosen as a chemical carcinogen because it can initiate DNA adduct or initiation stage (first stage) of skin carcinogenesis. DMBA is activated in the liver by modulating phase-1 detoxification enzyme cytochrome P450 and being converted into 3.4-diol-1,2-epoxide that can covalently bind to DNA, developing what is known as DNA adduct [11]. Moreover, the activation of DMBA causes transversion $A \rightarrow T$ at codon- 61 of the Hras1 gene and supports mutation of Hras1 as a critical event in skin carcinogenesis and methylation $\mathrm{Nr} 4 \mathrm{a} 3$ exon 3 of $\mathrm{CpG}$ domain $[12,13]$.

The initiated cells are promoted clonally by croton oil to promotion stage (second stage). During tumor promotion, the cells are lead to sustained epidermal hyperplasia, evidenced by the increase of nucleated cell layer and the increase of epidermis thickness. This initiated cell grows independently over neighboring cells and resulting loss of cell population. The result of this promotion stage is development of skin papilloma [14]. During two-stage skin carcinogenesis, there was no significant difference in body weight $(p>0.05)$ (Figure 1) but significant difference was found in the cumulative number of papilloma $(p<0.05)$ for all mice. The carcinogen control group (DMBA/CO) was significantly different compared to $5 \% \quad 5-\mathrm{FU}$ group and $5 \%$ imiquimod $(p=0.003)$ while for group therapy, a significant difference was found on $1 \% 5$-FU compared to $5 \%$ imiquimod $(p=0.000)$.

Papilloma consists of a stromal core surrounded by the hyperplastic epidermis (Figure $\mathbf{2 b}$ ). This promotion stage increases epidermal thickness, proliferation of epidermal keratinocytes, and increases DNA mutation synthesis. The central mass of tumor and necrotic cells are surrounded by neoplastic cells. Moreover, the epidermal keratinocytes are immature, therefore by contributing to parakeratosis, it is alternating with hyperkeratosis [15]. The papilloma as a precancerous stage may progress to invasive squamous cell carcinoma if the promoting agent is continually given.
Many studies have proven that tumor growth and development involve molecular process. This process involves multi-gene and multiple molecular levels that are found in multi-step carcinogenesis [16]. As a result, cells proliferate or divide uncontrollably due to the dysfunction of the disrupted cell cycle. One of the markers of proliferation that has been widely used is Ki67. Ki67 is a non-histone protein expressed by the nucleus during cell cycle phases (G1-M) [3]. The protein increases during the $M$-phase and being decreased during G1 and S-phases [4]. The expression of Ki67 is related to the growth fraction and absent during DNA repair process. This protein is regulated in the proteolytic pathway and controlled by cyclin B/cyclindependent kinase 2 [3].

Immunohistochemistry result showed that Ki67 expression in the normal group $(46.79 \pm 2.47)$ was lower than precancerous squamous cell without treatment. For therapy groups, the lowest Ki67 expression was found in $5-\mathrm{FU} 5 \%$ group $(\mathrm{p}=0.001)$ and 5 -FU $2 \%$ group $(p=0.006)$, while the highest Ki67 expression was found in imiquimod 5\%. Ki67 expression was increased in dysplasia condition such as in other types of cancer. The alteration of Ki67 level might be considered as an overall survival predictor in the clinic.

The increasing Ki67 level as a marker proliferation demonstrated that there was an abnormality in cell cycle regulation and adhesion molecules, such as Ecadherin and $\alpha$-catenin. Furthermore, the high proliferation conditions were triggered by activation of autocrine mechanism for several growth factors, such as TGF- $\alpha$ and EGF. Moreover, it can be influenced by DNA ploidy pattern and also correlates to locoregional recurrence [17-18].

5-FU therapy is known as an inhibitor of thymidylate synthase (TS) by binding to DNA or RNA and interrupting the nucleotide metabolism then trigger the apoptosis pathway [6]. 5-FU as a therapy for precancerous squamous cell acts to inhibit cell proliferation. Based on this research, we found that 5FU $2 \%$ and $5 \%$ concentration were proven to inhibit cell proliferation compared to standard therapy using imiquimod $5 \%$. The inhibition of cell proliferation was known as activation of intrinsic apoptosis pathway through potential membrane damage of cell mitochondria. This damage is stimulated by Bax translocation from the cytosol into the mitochondria that release the cytochrome-c. The cytochrome-c which is released into the cytosol binds to Apaf-1 and activates procaspase- 9 in apoptosome. Caspase- 9 activation causes activation of the caspase executor, in this case, caspase- 3 will fragment the target protein including poly (ADP-ribose) polymerase resulting in cell death and cease of proliferation [19].

The following cut-off value of $30 \%$ was used similar to SCC cases. Ki67 values were divided into two categories if the value was less than $30 \%(<30 \%)$, it was 
classified as low proliferation, while if the value was more than $30 \%(>30 \%)$, it was classified to high proliferation. This research resulted in 2 cases (8.3\%) classified as low proliferation, while 22 cases (91.67\%) were classified as high proliferation.

\section{CONCLUSION}

We conclude that 5-FU treatment during 4 weeks (week10-week14) showed a decrease of cumulative number of papilloma and immunohistochemistry analysis resulted that the lowest Ki67 expression was found in $5-\mathrm{FU} 5 \%$ group $(\mathrm{p}=0.001)$ and $5-\mathrm{FU} 2 \%$ group $(p=0.006)$ in comparison to imiquimod cream treatment.

\section{DECLARATIONS}

\section{Competing of Interest}

The authors declare no competing interests.

\section{Acknowledgment}

This research is sponsored by the National Cancer Center-Dharmais Cancer Hospital.

\section{REFERENCES}

1. Netscher DT, Leong M, Orengo I, Yang D, Berg C, Krishnan B. Cutaneous malignancies: melanoma and nonmelanoma types. Plast Reconstr Surg. 2011;127(3):37e-56e.

2. Singh M, Suman S, Shukla Y. New enlightenment of skin cancer chemoprevention through phytochemicals: In vitro and in vivo studies and the underlying mechanisms. Biomed Res Int. 2014;10(4):1-18.

3. Li LT, Jiang G, Chen Q, Zheng JN. Predict Ki67 is a promising molecular target in the diagnosis of cancer (review). Mol Med Rep.2015;11(3):1566-72.

4. Prihantono $P$, Muchamad $H$, Critian B, Daniel $S$, Haryasen $H$, Berti $N$, et al. Ki67 expression by immunohistochemistry and quantitative real time polymerase chain reaction as a predictor of clinical response to neoadjuvant chemotherapy in locally advanced breast cancer. J Oncol. 2017;2017:1-8.

5. Ceilley RI. Mechanisms of action of topical 5fluorouracil: Review and implications for the treatment of dermatological disorders. J Dermatolog Treat. 2012;23(2):83-9.

6. Zhang $N$, Yin $Y, X u$ SJ, Chen WS. 5-Fluorouracil: Mechanisms of resistance and reversal strategies. Molecules. 2008;13(8):1551-69.

7. Chinembiri TN, Gerber M, Plessis L, Preez J, Plessis J. Topical delivery of 5-Fluorouracil from pheroid TM formulations and the in vitro efficacy against human melanoma. AAPS Pharm SciTech. 2015;16(6):1390-9.

8. Sati J, Mohanty BP, Garg ML, Koul A. Pro-Oxidant role of silibininin DMBA/TPA Induced Skin Cancer: 1 HNMR metabolomic and biochemical study. PLoS One. 2016;11(7):1-23.

9. Qiblawi S, Dhanarasu S. Chemopreventive potential of fish oil against 7,12-dimethylbenz (a)anthracene and croton oil induced two-stage mouse skin. Biomed Res. 2017;28(6):2596-603.

10. Arora N, Koul A, Bansal MP. Chemopreventive activity of Azadirachta indica on two-stage skin carcinogenesis in murine model. Phyther Res. 2011;25(3):408-16.

11. Sharma J, Goyal PK. Chemoprevention of chemicalinduced skin cancer by Panax ginseng root extract. J Ginseng Res. 2015;39(3):265-73.

12. Abel EL, Angel JM, Kiguchi K, Digiovanni J. Multistage chemical carcinogenesis in mouse skin: Fundamentals and applications. Nat Protoc. 2011;4(9):1350-62.

13. Nassar D, Latil M, Boeckx B, Lambrechts D, Blanpain C. Genomic landscape of carcinogen-induced and genetically induced mouse skin squamous cell carcinoma. Nat Med. 2015;21(8):946-54.

14. Subramanian V, Venkatesan B, Tumala A, Vellaichamy E. Topical application of Gallic acid suppresses the7,12-DMBA /Croton oil induced twostep skin carcinogenesis by modulating antioxidants and MMP-2/ MMP-9 in Swiss albino mice. Food Chem Toxicol. 2014;66:44-5.

15. Rowert-Huber J, Patel MJ, Forshner T, Ulrich C, Eberle J, Kerl H, et al. Actinic keratosis is an early in situ squamous cell carcinoma: a proposal for reclassification. Br J Dermatol;156(3):8- 12

16. Gu J, Ren L, Wang X, Qu C, Zhang Y. Expression of livin, surviving and caspase-3 in prostatic cancer and their clinical significance. Int J Clin Exp Pathol. 2015;8(11):14034-9.

17. Deniz F,Dilek K,Hande M,Umit UM,Handan K.Ki-67 and caspase expression in breast carcinoma: Does variance in locational sampling exist? Int J Clin Exp Pathol. 2015;8(9):11305-13.

18. Berdjis N, Meye A, Nippgen J, Dittert D , Hakenberg $\mathrm{O}$, Baretton $\mathrm{GB}$, et al. Expression of $\mathrm{Ki}-67 \mathrm{In}$ squamous cell carcinoma of the penis. BJU Int. 2005;96(1):146-8.

19. Coutinho-Camillo CM, Lourenço SV, Puga RD, Damascena AS, TeshimaTHN, Kowalski LP, et al. Profile of apoptotic proteins in oral squamous cell carcinoma: A cluster analysis of 171 cases. Appl Cancer Res. 2017;37(1):2. 